\title{
Educational inequalities in young-adult mortality between the 1990s and the 2000s: regional differences in Belgium
}

\author{
Hannelore De Grande, ${ }^{*}$ Hadewijch Vandenheede and Patrick Deboosere
}

\begin{abstract}
Background: This study addresses educational inequalities in young-adult mortality between the 1990s and the 2000s by comparing trends in the three different regions in Belgium stratified by sex. Social inequalities in mortality are of major concern to public health but are rarely studied at young ages. Substantial health differences have been found between the Flemish (FR) and Walloon region (WR) concerning (healthy) life expectancy and avoidable mortality, but little is known about regional differentials in young-adult mortality, and comparisons with the Brussels-Capital Region (BCR) have thus far never been made.

Methods: Data are derived from record linkage between the Belgian censuses of 1991 and 2001 and register data on death and emigration for the periods 01/03/1991-01/03/1999 and 01/10/2001-01/10/2009. Analyses are restricted to young adults aged 25 to 34 years at the moment of each of the censuses. Absolute (directly standardized mortality rates (ASMRs)) and relative (mortality rate ratio using Poisson regression) measures were calculated.

Results: There is a significant drop in young-adult mortality between the 1990s and the 2000s in all regions and both sexes, with the strongest decline in the BCR (e.g. ASMR of men declined from 165.6 [151.1-180.1] per 100,000 person years to 73.8 [88.3-98.3]). The mortality rates remain highest in the WR in the 2000s Between the 1990s and the 2000s, a remarkable change in the educational distribution occurred as well, with much lower proportions of primary educated in all regions in the 2000s in favour of higher proportions in all other educational levels, especially in higher education. All educational groups show lower mortality over time, except for lower educated men in the FR.

Conclusions: There is a positive evolution towards lower mortality among the young-adult Belgian population. The WR trails behind in this evolution, which calls for tailored preventive actions. Educational inequalities are marked in all regions and time periods. A more general discussion is needed on the responsibility of society in rendering support and capability to enhance the state of well-being of those not able to achieve a high social position.
\end{abstract}

Keywords: Educational inequalities, Absolute and relative differences, Adolescent \& young-adult mortality, Regional differences

\section{Background}

Mortality declined steadily in the last decades in most western countries [1-3]. Despite this generally positive evolution, relative inequalities in morbidity and mortality have persisted or widened over time [4-6]. This trend is less obvious in mortality among the young (15- to 34year olds), with all-cause mortality declines sometimes masking increases in avoidable cause-specific mortality

\footnotetext{
* Correspondence: hannelore.de.grande@vub.ac.be

Department of Sociology - Interface Demography, Vrije Universiteit Brussel, Pleinlaan 5, 1050 Brussels (Elsene), Belgium
}

such as suicides, homicides and drug-related deaths [7-10]. Other research however found strong mortality declines over time in all-cause [11] and cause-specific mortality $[10,12]$, following the general trend at older ages.

Education is the most commonly used socioeconomic position (SEP) indicator when studying inequalities in young adulthood [13]. The obtained educational level is strongly determined by parental characteristics such as household income and fathers' occupation. For this paper the age group of 25-34 is selected because most people in Belgium have completed their formal education 
by the age of 25 . Education is then the most stable indicator for SEP, whereas other measures such as income or occupation are more prone to change in this life stage. The link between education and health/mortality is firmly established e.g. [6,14-16]. From young adulthood onwards, social inequalities increase following a social gradient that continues well into old age $[17,18]$. Education not only influences health outcomes through increased knowledge and insights but also indirectly through jobs with more benefits, a higher income and through a greater sense of control and social support $[16,19,20]$. Monitoring educational inequalities in mortality over time provides insight into the interplay of compositional changes in educational groups and inequalities in mortality between educational levels.

Regional differences in absolute and relative mortality inequalities have been observed in several European countries [21]. In Belgium, substantial regional differences have been found in avoidable mortality [22,23] and (healthy) life expectancy $[24,25]$. Belgium consists of three regions: the Flemish Region (FR - North), Walloon Region (WR south) and Brussels-Capital Region (BCR - centre). The Walloon Region (WR) does not only have a worse health status than the Flemish Region (FR); inequalities are also larger both in life expectancy and disability free life expectancy [24-26]. The worse economic situation in the WR is put forward as a main contributor to the persisting regional differences [25]. Yet, these studies did not include the BCR and did not have a specific focus on young adults. The BCR is often not included in these comparisons, because of the small population size in research using sampling designs [27]. This restriction does not hold for this paper, as exhaustive population data are used. Research in the $\mathrm{BCR}$ using these data found lower mortality rates over time among 15-to-34-year olds and persisting educational inequalities, especially among men [12], but did not compare the different regions. Leaving the BCR out of regional comparisons only allows for a partial insight into regional mortality inequalities, in particular because its metropolitan character entails higher income inequalities [28]. Mechanisms behind social inequalities in Belgium cannot be fully understood without accounting for this region as well.

This study addresses the evolution in educational inequalities in mortality among young adults between the 1990s and the 2000s. This study adds to the literature through its focus on young-adult mortality, on trends over time and through its inclusion of the BCR and thus comparison of the three Belgian regions. We respectively examine regional differences and trends in 1) all-cause mortality in young adults, 2) educational inequalities in young-adult mortality and 3) if the observed regional differences in educational inequalities are due to differences in the population composition between the regions in terms of nationality of origin and employment. These research questions will be dealt with stratified by gender.

\section{Methods}

\section{Data}

Data are derived from two Belgian censuses linked to death and emigration records of the national registry. These provide exhaustive information on the official population living in Belgium at the time of each census collection (01/03/1991 and 01/10/2001). Follow-up is possible due to linkage with national register data on deaths and emigrations for the respective periods 1991-1999 and 2001-2009. The cohort is semi-closed; no new entries (either by immigration or birth) are taken into account.

\section{Study population}

We restrict the analysis to young adults aged 25 to 34 at baseline. We observe two periods, 1991-1999 and 2001-2009, further broken down in two periods each of which contains four years of follow-up time: 01/03/ 1991-01/03/1995 (P1), 01/03/1995-01/03/1999 (P2), 01/ $10 / 2001-01 / 10 / 2005$ (P3) and 01/10/2005-01/10/2009 (P4). At each new interval, the age range of 25 to 34 years is recalculated to ascertain comparability between periods. For the exposure time calculation, we use age at entry for P1 and P3, and the recalculated age at the beginning of $\mathrm{P} 2$ and $\mathrm{P} 4$.

\section{Variables}

\section{Own educational level}

Four categories are used, following the ISCEDclassification: 1) no/primary, 2) lower secondary education, 3) higher secondary education, and 4) higher education. Missing values on education are included as separate categories in the analyses. We observe a shift towards higher educational levels over time, in all regions (Table 1). For example, while $20.7 \%$ of the Flemish women had a degree of primary education in 1991 , this is only $3.8 \%$ in 2001. Furthermore, in 2001 there is a higher share of both low and higher educated young persons in the BCR in both sexes compared to the other regions, a trend that is still apparent in recent observations [28].

The composition of the young population not only differs regionally in terms of educational level, but also in terms of other factors. The BCR attracts migrants from all over the world and thus consists of a large population of non-Belgian origin, especially in the youngest age groups [28]. The influx of migration in 2001 made differences with 1991 even more substantial (Table 1). Some nationality groups have lower or higher mortality risks compared to the native Belgian population [29,30], which might impact a regional comparison. Nationality 
Table 1 Distribution of population characteristics among young adults (25-34 yrs) in Belgium according to sex, period and region (in column \%)

\begin{tabular}{|c|c|c|c|c|c|c|c|c|c|c|c|c|c|}
\hline & & \multicolumn{6}{|l|}{ MEN } & \multicolumn{6}{|c|}{ WOMEN } \\
\hline & & \multicolumn{3}{|l|}{1991} & \multicolumn{3}{|l|}{2001} & \multicolumn{3}{|l|}{1991} & \multicolumn{3}{|l|}{2001} \\
\hline & & $\overline{F R}$ & BCR & WR & $\overline{F R}$ & BCR & WR & FR & BCR & WR & FR & BCR & WR \\
\hline \multicolumn{14}{|l|}{ Educational level } \\
\hline Primary & & 17.36 & 21.79 & 21.41 & 4.03 & 8.48 & 5.94 & 20.65 & 22.98 & 21.42 & 3.75 & 8.86 & 4.87 \\
\hline Lower sec & & 21.57 & 18.83 & 18.83 & 15.34 & 17.60 & 22.65 & 15.03 & 15.45 & 22.42 & 11.33 & 15.04 & 18.26 \\
\hline Higher sec & & 35.33 & 24.40 & 32.03 & 45.18 & 26.94 & 40.06 & 35.61 & 23.71 & 30.65 & 41.05 & 24.31 & 35.80 \\
\hline \multirow[t]{2}{*}{ Higher } & & 25.74 & 34.98 & 20.95 & 35.45 & 46.98 & 31.34 & 28.72 & 37.86 & 25.51 & 43.86 & 51.78 & 41.07 \\
\hline & Missing & $(5.17)$ & $(21.91)$ & $(6.71)$ & $(5.07)$ & $(19.35)$ & $(8.36)$ & $(4.56)$ & $(19.53)$ & $(5.26)$ & (3.80) & $(16.99)$ & $(6.08)$ \\
\hline \multicolumn{14}{|l|}{ Nationality of origin } \\
\hline Belgian & & 92.68 & 58.86 & 78.89 & 93.38 & 60.18 & 80.01 & 88.49 & 42.82 & 77.17 & 88.15 & 42.68 & 77.58 \\
\hline European/Western & & 4.29 & 20.11 & 16.09 & 3.91 & 20.45 & 15.72 & 5.26 & 22.24 & 15.75 & 5.20 & 24.58 & 15.37 \\
\hline Maghrebin/Turkish & & 1.66 & 12.88 & 2.51 & 1.58 & 12.14 & 2.03 & 3.95 & 23.52 & 4.18 & 3.39 & 19.59 & 3.41 \\
\hline Other & & 1.37 & 8.15 & 2.51 & 1.13 & 7.23 & 2.23 & 2.30 & 11.42 & 2.91 & 3.27 & 13.14 & 3.64 \\
\hline \multicolumn{14}{|l|}{ Employment situation } \\
\hline Self-employed & & 13394 & 14.44 & 13.08 & 10.50 & 8.70 & 8.09 & 8.57 & 7.63 & 7.63 & 6.32 & 4.73 & 4.42 \\
\hline Employee & & 35.46 & 38.28 & 31.76 & 42.59 & 44.21 & 39.52 & 45.81 & 48.52 & 42.43 & 55.86 & 47.67 & 46.99 \\
\hline (Un) Skilled worker & & 42.39 & 25.25 & 38.57 & 27.75 & 14.47 & 25.07 & 17.95 & 9.77 & 10.70 & 10.18 & 4.99 & 6.30 \\
\hline Job seeker & & 3.72 & 11.40 & 9.69 & 4.48 & 16.56 & 12.09 & 12.42 & 15.29 & 20.40 & 7.20 & 19.21 & 19.43 \\
\hline Not working, not seeking a job & & 0.82 & 1.31 & 1.75 & 1.80 & 2.76 & 2.39 & 9.39 & 10.23 & 13.16 & 7.74 & 10.65 & 10.15 \\
\hline Working, job unknown & & 1.72 & 3.32 & 2.10 & 9.08 & 7.93 & 9.58 & 2.96 & 3.23 & 2.45 & 7.90 & 7.29 & 7.89 \\
\hline \multirow[t]{2}{*}{ Other } & & 1.95 & 6.01 & 3.06 & 3.80 & 5.37 & 3.26 & 3.16 & 5.54 & 3.23 & 4.80 & 5.46 & 4.82 \\
\hline & Missing & $(3.07)$ & $(18.47)$ & $(5.85)$ & (3.73) & $(17.36)$ & $(6.78)$ & (2.96) & $(15.64)$ & $(4.55$ & (3.19) & $(15.99)$ & $(5.71)$ \\
\hline
\end{tabular}

Data: census 1991, 2001 linked to national register, own calculations.

$\%$ are calculated exclusive of missings; between brackets: \% of missings per indicator compared to the total.

of origin is included in four categories in our analyses: 1) Belgian, 2) European/Western (including all EU-15 countries, USA, Canada, Japan, Australia \& New Zealand), 3) Maghrebin (all North-African countries except Egypt)/ Turkish, and 4) other.

As inequalities in mortality exist between the employed versus the non-employed [16] and the composition of employed/non-employed differs between the regions and increases over time, employment situation is another important factors that needs to be adjusted for. It is operationalized as a combination of information on the type of occupation and being employed or not. It contains seven categories: 1) selfemployed, 2) employee, 3) (un) skilled worker, 4) job seeker, 5) not working and not seeking a job, 6) working but unknown sort of job and 7) other (including students, $<1 \%$ of the total population). There is a shift towards more employees and less (skilled) workers in 2001 compared to 1991. The percentage of (skilled) workers is a lot lower in the BCR than in the other regions for both men and women.

\section{Analysis}

Both relative and absolute inequalities in mortality are calculated. We computed age-standardised all-cause mortality rates (ASMRs), directly standardised to the European population of 2013 [31]. Absolute mortality decline is calculated between each period and between the first (1991-1995) and the last period (2005-2009). Relative mortality decline is calculated by dividing the absolute mortality decline of the latter period by the ASMR of the former period. It is calculated between each period and between 1991-1995 and 2005-2009. Furthermore, mortality rate ratios (MRRs) are calculated using Poisson regression. In these models, nationality of origin and employment situation are used as controls to test the robustness of the educational inequalities. The Poisson regressions are carried out with STATA MP 13.1 and stratified by region and period. To test if relative inequalities significantly changed over time, the 1991 and 2001 census were integrated to include the interaction between period and educational level (see Table 2). The terminology '1990s' and '2000s' is used 
Table 2 All-cause mortality rate ratios (MRR): interaction terms between educational level and period by region and sex (reference category $=$ higher education)

\begin{tabular}{|c|c|c|c|c|c|c|c|}
\hline & \multicolumn{2}{|l|}{ FR } & \multicolumn{2}{|l|}{ BCR } & \multicolumn{2}{|l|}{ WR } \\
\hline & & $\overline{\text { MRR }}$ & sign. & $\overline{\text { MRR }}$ & sign. & $\overline{\text { MRR }}$ & sign. \\
\hline \multirow[t]{6}{*}{$\overline{\mathrm{MEN}}$} & Higher sec 91 & 1.69 & & 1.62 & & 1.54 & \\
\hline & Higher sec 01 & 2.09 & * & 1.96 & & 2.17 & $* *$ \\
\hline & Lower sec 91 & 1.95 & & 2.04 & & 1.91 & \\
\hline & Lower sec 01 & 3.01 & $* * *$ & 2.53 & & 2.93 & $* *$ \\
\hline & Primary 91 & 2.83 & & 2.28 & & 2.87 & \\
\hline & Primary 01 & 3.97 & * & 3.10 & & 3.67 & \\
\hline \multirow[t]{6}{*}{ WOMEN } & Higher sec 91 & 1.28 & & 1.93 & & 1.06 & \\
\hline & Higher sec 01 & 1.50 & & 1.18 & & 1.53 & $*$ \\
\hline & Lower sec 91 & 1.56 & & 2.20 & & 1.30 & \\
\hline & Lower sec 01 & 2.17 & * & 0.99 & * & 1.73 & \\
\hline & Primary 91 & 1.87 & & 2.37 & & 1.86 & \\
\hline & Primary 01 & 3.67 & $* * *$ & 2.35 & & 2.68 & \\
\hline
\end{tabular}

Combined dataset of census 1991 and 2001, own calculations. $\mathrm{FR}=$ Flemish Region, $\mathrm{BCR}=$ Brussels-Capital Region, $\mathrm{WR}=$ Walloon Region Sign. = Statistical significant difference between period 1991-1995 and 2001-2005.

*: $p<0.050 ;{ }^{* *}: p<0.010 ;{ }^{* * *}: p<0.001$.

to designate the periods $1991-1999$ and 2001-2009. If we refer to a specific sub period (e.g. 1991-1995), the period is specified in the text. Each model is also controlled by age and presented separately for men and women.

\section{Results}

\section{General mortality changes over time}

To answer the first research question concerning regional differences in all-cause mortality over time, we make use of Figure 1 (men) and Figure 2 (women). Young-adult mortality decreased considerably over time, in all regions, and in both men and women.

In 1991-1995 male mortality rates are clearly smallest in the FR $\left(\mathrm{ASMR}_{\mathrm{FR}-91}=118.3\right.$ [113.4-123.2]) compared to the other regions, having similar mortality rates $\left(\mathrm{ASMR}_{\mathrm{BCR}-91}=165.6\right.$ [95\% CI 151.1-180.1]; $\mathrm{ASMR}_{\mathrm{WR}-91}=$ 178.3 [170.0-186.6]). This pattern changes over time, as the mortality decline was most pronounced in men in the BCR. In 2001-2005, mortality rates become similar between the FR and the BCR, and in 2005-2009 mortality is even significantly lower in the BCR than in the FR $\left(\mathrm{ASMR}_{\mathrm{BCR}-05}=73.8\right.$ [63.8-84.3]; $\mathrm{ASMR}_{\mathrm{FR}-05}=93.3$ [88.398.3]). The decline is smallest in the FR, with a relative mortality decline of $21 \%$ over the total observation period (1991-2009) compared to $28 \%$ in the WR and 55\% in the BCR (not in Figure). The WR still shows the highest mortality rates at the end of the observation period $\left(\mathrm{ASMR}_{\mathrm{WR}-05}=128.8\right.$ [121.0-136.6]).

The mortality pattern among women is similar to that of men, although the decline over time in the BCR is more modest (Figure 2). Relative mortality declines range from $26 \%$ in the WR and $27 \%$ in the FR to $34 \%$ in the BCR (not in Figure). Contrary to the regional mortality pattern among men, young-adult women living in the FR still have the lowest mortality in 2005-2009 $\left(\mathrm{ASMR}_{\mathrm{FR}-05}=39.2[36.0-42.4]\right)$.

\section{Educational mortality pattern over time}

Our second research question addresses the regional differences in educational inequalities in all-cause mortality over time. Table 3 shows educational mortality differences over time for men, with person years, mortality rates and number of deaths for each category, period and region. Additional file 1: Table S1 shows the related

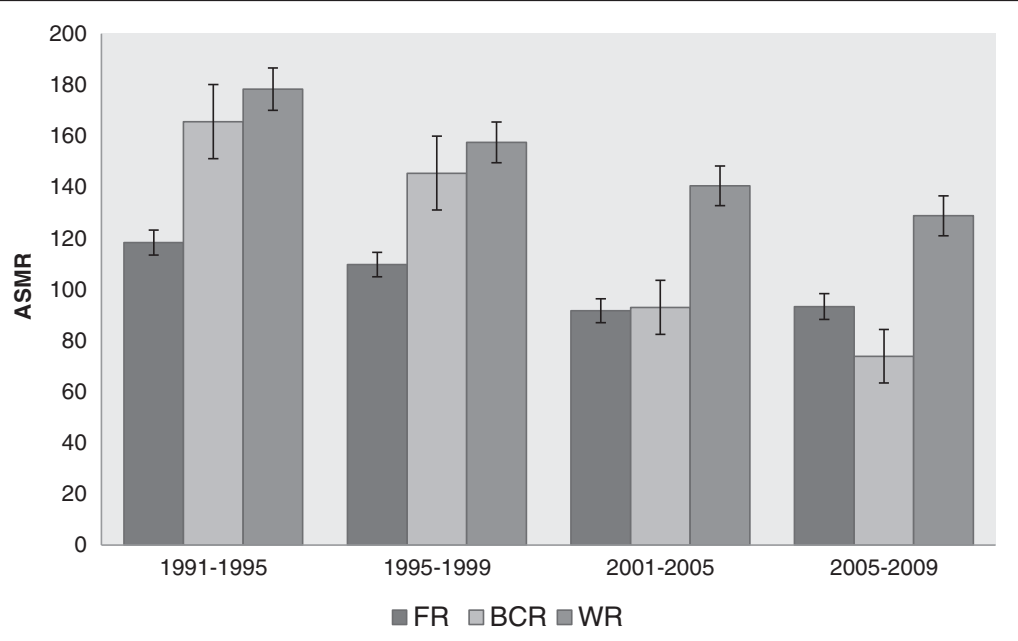

Figure 1 Age-standardized mortality rates (ASMRs) with confidence intervals per 100,000 person years in young-adult MEN (25-34 yrs) from 1991 until 2009 in the three Belgian regions. FR= Flemish Region, BCR=Brussels-Capital Region, WR= Walloon Region. 


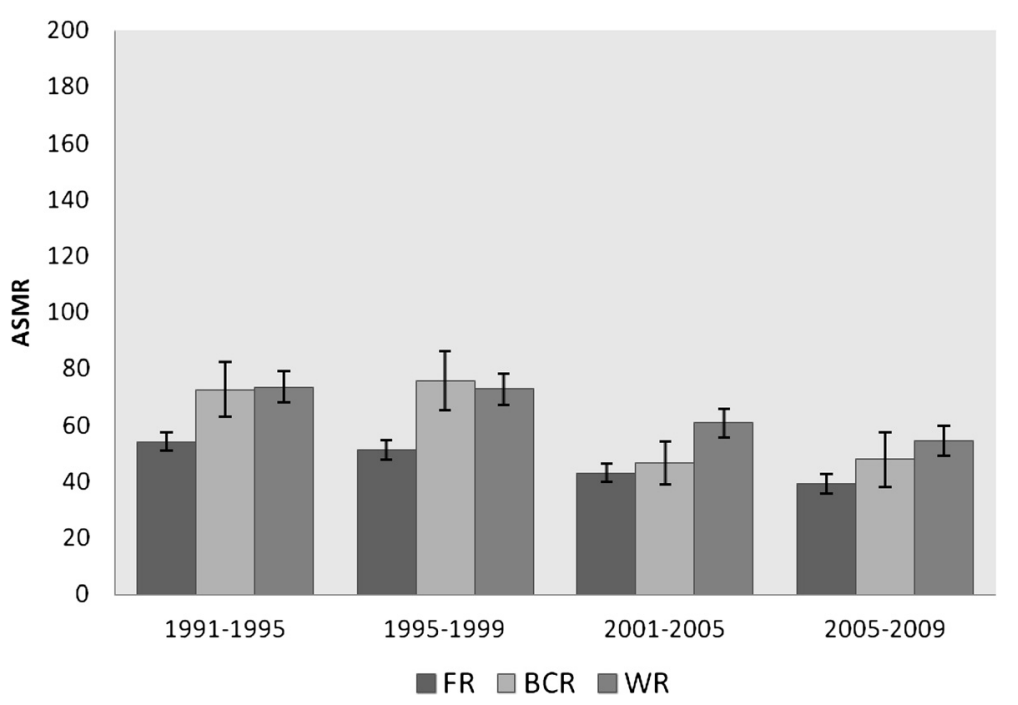

Figure 2 Age-standardized mortality rates (ASMRs) with confidence intervals per 100,000 person years in young-adult WOMEN (25-34 yrs) from 1991 until 2009 in the three Belgian regions. FR= Flemish Region, BCR=Brussels-Capital Region, WR= Walloon Region.

absolute and relative mortality differences over time. In the FR, mortality declined most among the higher educated $\left(\mathrm{ASMR}_{\mathrm{FR}-05-\text { higher }}=42.5[36.8-48.1]\right.$ compared to $\mathrm{ASMR}_{\mathrm{FR}-91 \text {-higher }}=64.2$ [56.9-71.6]) (Additional file 1: Table S1). There is a relative mortality increase of $18 \%$ among the primary educated and $11 \%$ among the lower secondary educated in 2005-2009 compared to 20012005 (Table 4). As a result of this, overall mortality decline is smaller in the FR and both absolute and relative inequalities have increased over time. In the BCR, we observe substantial mortality declines in almost all educational levels (especially between 1995 and 2001: ranging from a $26 \%$ decrease among the lower secondary educated to $41 \%$ among the higher educated Additional file 1: Table S1). In 2005-2009, inequalities increased again because of an increase in mortality among the primary educated while there are further decreases in the other educational categories. In the WR, there is a strong decrease in educational inequalities in 2001-2005, followed by a small increase in inequalities in 2005-2009.

The educational pattern of women in the FR (Table 4) is comparable to that of men. While the highest educated groups have lower mortality rates in the 2000s, there is an increase in mortality in the lowest educated (e.g. $\mathrm{ASMR}_{\mathrm{FR}-91 \text {-primary }}=70.3$ [61.8-78.9]), $\mathrm{ASMR}_{\mathrm{FR}-01 \text {-primary }}=$ 104.4 [77.5-131.3]). Mortality among the highest educated decreased with $34 \%$, leading to larger inequalities over time (Additional file 2: Table S2). In the BCR, there is a clear split between those with primary education and the other educational groups in 2001-2005. There is only a small mortality decline in the primary educated $(8 \%)$, while the decline in other groups ranges from
36 to $53 \%$. In $2005-2009$, a further mortality decline is only observed in the highest educated women, leading to pronounced differences between the highest educated and the other educational levels. In the WR, trends in educational inequalities are more substantial over time, with increases among the lowest educated (59\%) and large decreases over time among the highest educated (44\%).

As already detailed in Table 1, a remarkable change in the educational distribution occurred in all regions and in both men and women. Primary educated young adults become a small group in the 2000s (e.g. Additional file 1: Table S1: PY in the primary educated men of the WR in 1991: 199,386 compared to 48,784 in 2001). The overall mortality decline is thus not only the result of a decrease in mortality in most educational groups, but is also due to a shrinking low-educated group with high mortality risks compared to the higher educated. The latter group expanded most over time (e.g. in the BCR, PY in women increased from 94,292 in 1991 to 136,211 in 2001).

\section{Robustness of regional differences in educational inequalities in mortality after controlling for employment situation and nationality of origin}

To answer our third research question, age-adjusted mortality rate ratios (MRRs) are presented in Table 5 (men) and Table 6 (women). Model 1 is adjusted for age, model 2 is controlled for age and employment situation and model 3 for age, employment situation and nationality of origin. Trends are presented by comparing the first period after each census. Analyses for the other periods are not presented because we lack updated information on the employment situation in 1995 and 2005. A full table with this information is available on request. 
Table 3 All-cause age-standardised mortality rates (ASMRs) and confidence intervals (CI) per 100,000 person years (PY) among young-adult MEN (25-34 years) in Belgium for 4 periods of follow-up

\begin{tabular}{|c|c|c|c|c|c|c|c|c|c|c|c|c|c|c|c|c|c|}
\hline & & \multicolumn{4}{|c|}{ 1991-1995 } & \multicolumn{4}{|c|}{ 1995-1999 } & \multicolumn{4}{|c|}{ 2001-2005 } & \multicolumn{4}{|c|}{ 2005-2009 } \\
\hline & & PY & ASMR & $95 \% \mathrm{Cl}$ & d & PY & ASMR & $95 \% \mathrm{Cl}$ & d & PY & ASMR & $95 \% \mathrm{Cl}$ & $d$ & PY & ASMR & $95 \% \mathrm{Cl}$ & d \\
\hline \multirow[t]{6}{*}{$F R$} & Higher & 462,547 & 64.2 & [56.9-71.6] & 294 & 488,927 & 60.1 & [56.2-66.9] & 293 & 538.763 & 44.3 & [38.6-49.91] & 238 & 517.494 & 42.5 & [36.8-48.1] & 218 \\
\hline & Higher sec & 639,489 & 108.6 & [100.4-116.7] & 686 & 679,895 & 105.3 & [97.5-113.0] & 716 & 690,424 & 92.4 & [85.2-99.5] & 637 & 647,849 & 100.1 & [92.4-107.8] & 648 \\
\hline & Lower sec & 389,240 & 124.3 & [113.3-135.4] & 484 & 328,413 & 127.2 & [114.9-139.5] & 420 & 234,054 & 136.0 & [120.8-151.3] & 314 & 185,247 & 150.6 & [132.9-168.3] & 279 \\
\hline & Primary & 312,359 & 180.8 & [165.9-195.8] & 567 & 227,664 & 178.3 & [160.6-196.1] & 403 & 61,154 & 178.5 & [144.3-212.7] & 108 & 44,120 & 210.6 & [167.7-253.5] & 93 \\
\hline & Missing & 92,453 & 219.6 & [189.2-250.0] & 202 & 85,805 & 180.6 & [152.2-209.1] & 155 & 73,965 & 227.0 & [192.7-261.3] & 168 & 59,172 & 197.6 & [161.8-233.4] & 117 \\
\hline & Total & $1,896,088$ & 118.3 & [113.4-123.2] & 2,233 & $1,810,704$ & 109.7 & [104.9-114.5] & 1,987 & $1,598.360$ & 91.7 & [87.0-96.3] & 1,465 & $1,453,882$ & 93.3 & [88.3-98.3] & 1,355 \\
\hline \multirow[t]{6}{*}{$B C R$} & Higher & 83,373 & 99.2 & [77.3-121.2] & 79 & 81,858 & 73.2 & [54.5-91.9] & 60 & 121,849 & 43.4 & [31.7-55.1] & 53 & 107,015 & 34.6 & [23.4-45.7] & 37 \\
\hline & Higher sec & 59,620 & 156.8 & [124.2-189.4] & 91 & 59,416 & 133.0 & [104.3-163.7] & 79 & 71,606 & 86.1 & [64.5-107.7] & 61 & 67,354 & 73.8 & [53.2-94.3] & 50 \\
\hline & Lower sec & 45,681 & 194.6 & [154.2-235.0] & 89 & 37,707 & 149.9 & [111.0-188.8] & 57 & 46,869 & 111.2 & [81.0-141.5] & 52 & 37,048 & 104.5 & [71.7-137.3] & 39 \\
\hline & Primary & 52,911 & 220.1 & [180.0-260.1] & 116 & 41,532 & 223.0 & [177.4-268.6] & 92 & 22,469 & 133.1 & [85.8-180.4] & 31 & 14.221 & 159.6 & [90.6-228.5] & 22 \\
\hline & Missing & 63,318 & 200.0 & [165.1-234.9] & 127 & 48,040 & 209.3 & [168.4-250.0] & 101 & 56,121 & 176.4 & [141.7-211.1] & 99 & 35,912 & 123.9 & [87.7-160.1] & 45 \\
\hline & Total & 304,903 & 165.6 & [151.1-180.1] & 502 & 268,553 & 145.4 & [131.0-159.9] & 389 & 318,915 & 92.9 & [82.4-103.5] & 296 & 261,550 & 73.8 & [63.4-84.3] & 193 \\
\hline \multirow[t]{6}{*}{ WR } & Higher & 193,715 & 93.3 & [79.7-107.0] & 180 & 205,664 & 60.9 & [50.2-71.6] & 125 & 256,107 & 57.3 & [48.0-66.6] & 147 & 252,537 & 63.4 & [53.6-73.2] & 160 \\
\hline & Higher sec & 299,972 & 143. & [129.5-156.8] & 428 & 313,941 & 143.0 & [129.7-156.2] & 449 & 329,706 & 124.8 & [112.7-136.8] & 411 & 319,531 & 116.2 & [104.3-128.0] & 371 \\
\hline & Lower sec & 239,146 & 178.2 & [161.3-195.1] & 426 & 207,759 & 168.3 & [150.6-186.1] & 347 & 186,321 & 170.3 & [151.5-189.1] & 316 & 150,432 & 190.0 & [168.0-211.9] & 289 \\
\hline & Primary & 199,386 & 268.8 & [246.0-291.6] & 537 & 155,559 & 268.3 & [242.6-294.0] & 425 & 48,784 & 212.8 & [171.5-254.1] & 104 & 35,120 & 246.0 & [193.7-298.3] & 87 \\
\hline & Missing & 62,989 & 320.4 & [275.8-364.9] & 200 & 58,602 & 234.0 & [194.9-273.2] & 137 & 70,545 & 387.6 & [341.8-433.4] & 274 & 57,422 & 251.7 & [210.8-292.7] & 145 \\
\hline & Total & 995,208 & 178.3 & [170.0-186.6] & 1,771 & 941,525 & 157.5 & [149.5-165.5] & 1,483 & 891,461 & 140.5 & [132.7-148.2] & 1,252 & 815,041 & 128.8 & [121.0-136.6] & 1,052 \\
\hline
\end{tabular}

Data: census 1991, 2001 linked to national register, own calculations.

$F R=$ Flemish Region, $B C R=$ Brussels-Capital Region, $W R=$ Walloon Region.

$d=$ number of deaths. 
Table 4 All-cause age-standardised mortality rates (ASMRs) and confidence intervals (CI) per 100,000 person years (PY) among young-adult WOMEN

(25-34 years) in Belgium for 4 periods of follow-up

\begin{tabular}{|c|c|c|c|c|c|c|c|c|c|c|c|c|c|c|c|c|c|}
\hline & & \multicolumn{4}{|c|}{ 1991-1995 } & \multicolumn{4}{|c|}{ 1995-1999 } & \multicolumn{4}{|c|}{ 2001-2005 } & \multicolumn{4}{|c|}{ 2005-2009 } \\
\hline & & PY & ASMR & $95 \% \mathrm{Cl}$ & d & PY & ASMR & $95 \% \mathrm{Cl}$ & d & PY & ASMR & $95 \% \mathrm{Cl}$ & d & PY & ASMR & $95 \% \mathrm{Cl}$ & d \\
\hline \multirow[t]{6}{*}{ FR } & Higher & 496,695 & 38.0 & [32.5-43.6] & 183 & 561,129 & 38.8 & [33.6-44.0] & 214 & 657,477 & 27.7 & {$[23.6-31.7]$} & 181 & 664,075 & 25.1 & [21.3-29.0] & 166 \\
\hline & Higher sec & 619,162 & 48.4 & [42.8-53.9] & 295 & 649,760 & 46.1 & [408.8-51.3] & 297 & 617,636 & 41.8 & [36.7-46.9] & 260 & 560,428 & 40.8 & [35.5-46.0] & 229 \\
\hline & Lower sec & 260,170 & 59.7 & [50.4-69.1] & 156 & 211,952 & 48.5 & [39.0-58.1] & 102 & 170,246 & 61.5 & [49.6-73.4] & 108 & 121,249 & 65.1 & [508-79.4] & 80 \\
\hline & Primary & 358,004 & 70.3 & [61.8-78.9] & 264 & 245,618 & 88.6 & [76.4-100.8] & 219 & 56,266 & 104.4 & [77.5-131.3] & 60 & 39,302 & 80.0 & [51.1-108.9] & 30 \\
\hline & Missing & 79,179 & 94.4 & [72.8-115.9] & 74 & 74,732 & 84.2 & [63.4-105.0] & 63 & 53,352 & 115.9 & [81.1-144.7] & 62 & 45,163 & 121.9 & [89.7-154.1] & 55 \\
\hline & Total & $1,813,210$ & 54.2 & [50.8-57.6] & 972 & $1,743,191$ & 51.2 & [47.9-54.6] & 895 & $1,554,977$ & 42.9 & [39.7-46.2] & 671 & $1,430,217$ & 39.2 & {$[36.0-42.4]$} & 560 \\
\hline \multirow[t]{6}{*}{$B C R$} & Higher & 94,292 & 36.8 & {$[24.2-49.3]$} & 34 & 93,305 & 57.0 & {$[41.3-72.7]$} & 52 & 136,211 & 36.4 & [26.1-46.6] & 49 & 122,711 & 25.6 & [16.6-34.7] & 31 \\
\hline & Higher sec & 60,133 & 73.0 & [50.8-95.2] & 42 & 57,706 & 83.7 & [59.7-107.8] & 47 & 65,268 & 42.6 & [26.8-58.4] & 28 & 62,336 & 58.0 & [38.6-77.4] & 35 \\
\hline & Lower sec & 38,751 & 82.5 & [53.9-111.0] & 32 & 29,772 & 77.8 & [46.6-108.9] & 24 & 40,575 & 36.2 & [17.9-54.5] & 15 & 31,780 & 62.9 & [35.3-90.6] & 20 \\
\hline & Primary & 57,969 & 89.6 & [65.2-114.0] & 52 & 43,490 & 93.2 & [65.2-121.2] & 43 & 23,764 & 85.9 & [49.0-122.8] & 21 & 16,452 & 107.9 & [56.0-159.9] & 17 \\
\hline & Missing & 57,142 & 108.2 & [81.2-135.8] & 61 & 44,511 & 77.9 & [52.1-103.7] & 35 & 47,725 & 66.1 & [42.8-89.4] & 31 & 32,234 & 70.8 & [41.9-99.8] & 23 \\
\hline & Total & 308,287 & 72.7 & [63.1-82.4] & 221 & 268,784 & 75.8 & [65.3-86.6] & 201 & 313,543 & 46.5 & [38.9-54.1] & 144 & 265,513 & 47.8 & [39.4-56.1] & 126 \\
\hline \multirow[t]{6}{*}{ WR } & Higher & 233,950 & 54.4 & [44.8-64.0] & 125 & 258,460 & 50.0 & [41.3-58.7] & 127 & 338,390 & 37.1 & [30.6-43.7] & 124 & 347,692 & 30.3 & {$[24.5-36.1]$} & 105 \\
\hline & Higher sec & 283,532 & 57.0 & [48.1-65.9] & 160 & 304,334 & 53.4 & [45.1-61.7] & 160 & 296,338 & 57.0 & [48.4-65.6] & 169 & 279,680 & 54.3 & [45.7-62.9] & 92 \\
\hline & Lower sec & 206,043 & 70.8 & [59.4-82.3] & 147 & 170.027 & 84.0 & [70.4-97.5] & 149 & 151,268 & 65.5 & [52.6-78.5] & 100 & 111.813 & 80.0 & [63.3-96.6] & 92 \\
\hline & Primary & 197,123 & 101.3 & [87.3-115.2] & 204 & 141,689 & 116.5 & [98.4-134.6] & 166 & 40,175 & $102.6]$ & [70.9-134.2] & 42 & 26,517 & 161.5 & [113.0-209.9] & 45 \\
\hline & Missing & 48,102 & 154.6 & [119.0-190.3] & 73 & 48,236 & 149.4 & [114.9-183.9] & 72 & 49,447 & 198.3 & [159.0237.5] & 98 & 41,856 & 118.8 & [85.8-151.7] & 50 \\
\hline & Total & 968,750 & 73.6 & [68.2-79.0] & 709 & 922,746 & 72.9 & {$[67.4-78.4]$} & 674 & 875,616 & 60.8 & [55.7-66.0] & 533 & 807,557 & 54.6 & [49.5-59.7] & 384 \\
\hline
\end{tabular}

Data: census 1991, 2001 linked to national register, own calculations.

$F R=$ Flemish Region, $B C R=$ Brussels-Capital Region, $W R=$ Walloon Region

$d=$ number of deaths. 
Table 5 All-cause mortality rate ratios and confidence intervals among young-adult MEN in Belgium by region for 1991-1995 and 2001-2005 (reference category = higher education)

\begin{tabular}{|c|c|c|c|c|c|c|c|}
\hline & & \multicolumn{3}{|l|}{$91-95$} & \multicolumn{3}{|l|}{ 01-05 } \\
\hline & & Model 1 & Model 2 & Model 3 & Model 1 & Model 2 & Model 3 \\
\hline \multirow[t]{6}{*}{$\overline{\mathrm{FR}}$} & Higher sec & $1.69^{* * *}$ & $1.71^{* * *}$ & $1.70^{* * *}$ & $2.09 * * *$ & $1.77^{* * *}$ & $1.77^{* * *}$ \\
\hline & & {$[1.48,1.94]$} & {$[1.48,1.97]$} & {$[1.47,1.96]$} & {$[1.80,2.43]$} & {$[1.50,2.08]$} & {$[1.51,2.09]$} \\
\hline & Lower sec & $1.94^{* * *}$ & $1.86^{* * *}$ & $1.87^{* * *}$ & $3.04^{* * *}$ & $2.28^{* * *}$ & $2.32^{* * *}$ \\
\hline & & {$[1.68,2.24]$} & {$[1.59,2.19]$} & {$[1.59,2.19]$} & {$[2.57,3.60]$} & {$[1.89,2.75]$} & {$[1.92,2.80]$} \\
\hline & Primary & $2.81^{* * *}$ & $2.23^{* * *}$ & $2.27^{* * *}$ & $4.01^{* * *}$ & $2.31^{* * *}$ & $2.48^{* * *}$ \\
\hline & & {$[2.44,3.24]$} & {$[1.91,2.61]$} & {$[1.94,2.66]$} & {$[3.19,5.03]$} & {$[1.80,2.95]$} & {$[1.93,3.19]$} \\
\hline \multirow[t]{6}{*}{$B C R$} & Higher sec & $1.63^{* *}$ & $1.68^{* *}$ & $1.60^{* *}$ & $1.96^{* * *}$ & $1.68^{*}$ & $1.72^{* *}$ \\
\hline & & {$[1.20,2.20]$} & {$[1.22,2.30]$} & {$[1.17,2.20]$} & {$[1.36,2.84]$} & {$[1.14,2.49]$} & {$[1.17,2.55]$} \\
\hline & Lower sec & $2.04^{* * *}$ & $1.89^{* * *}$ & $1.96^{* * *}$ & $2.53^{* * *}$ & $1.93^{* *}$ & $2.05^{* * *}$ \\
\hline & & {$[1.51,2.76]$} & {$[1.36,2.62]$} & {$[1.41,2.72]$} & {$[1.73,3.71]$} & {$[1.27,2.93]$} & {$[1.35,3.12]$} \\
\hline & Primary & $2.27^{* * *}$ & $1.74^{* * *}$ & $1.84^{* * *}$ & $3.11^{* * *}$ & $2.08^{* *}$ & $2.34^{* * *}$ \\
\hline & & {$[1.71,3.03]$} & {$[1.26,2.40]$} & {$[1.33,2.54]$} & {$[2.00,4.85]$} & {$[1.29,3.38]$} & {$[1.44,3.82]$} \\
\hline \multirow[t]{6}{*}{ WR } & Higher sec & $1.54^{* * *}$ & $1.62^{* * *}$ & $1.59^{* * *}$ & $2.17^{* * *}$ & $1.90^{* * *}$ & $1.88^{* * *}$ \\
\hline & & {$[1.30,1.83]$} & {$[1.35,1.94]$} & {$[1.32,1.90]$} & {$[1.80,2.62]$} & {$[1.55,2.32]$} & {$[1.54,2.29]$} \\
\hline & Lower sec & $1.91^{* * *}$ & $1.87^{* * *}$ & $1.86^{* * *}$ & $2.94^{* * *}$ & $2.27^{* * *}$ & $2.25^{* * *}$ \\
\hline & & {$[1.60,2.27]$} & {$[1.55,2.26]$} & {$[1.54,2.24]$} & {$[2.42,3.58]$} & {$[1.83,2.81]$} & {$[1.81,2.78]$} \\
\hline & Primary & $2.86^{* * *}$ & $2.22^{* * *}$ & $2.21^{* * *}$ & $3.69 * * *$ & $2.27^{* * *}$ & $2.29 * * *$ \\
\hline & & {$[2.42,3.39]$} & {$[1.84,2.68]$} & {$[1.83,2.67]$} & {$[2.87,4.75]$} & {$[1.73,2.99]$} & {$[1.74,3.02]$} \\
\hline
\end{tabular}

Data: census 1991, 2001 linked to national register, own calculations.

${ }^{* * *}: \mathrm{p}<0.001 ;{ }^{* *}: \mathrm{p}<0.010 ;{ }^{*}: \mathrm{p}<0.050$.

$\mathrm{FR}=$ Flemish Region, $\mathrm{BCR}=$ Brussels-Capital Region, $\mathrm{WR}=$ Walloon Region

Model 1: Controlled by age/Model 2: Controlled by age and employment situation/Model 3: Controlled by age, employment situation and nationality of origin.

Table 5 shows that educational inequality in male mortality is increasing in all regions between 1991-1995 and 2001-2005, especially in primary and lower secondary educated men (e.g. $\mathrm{MRR}_{\mathrm{FR}-91 \text {-primary-model } 1}=2.81 \quad$ [2.443.24] compared to MRR WR-01-primary-model $1=4.01$ [3.195.03]). The difference between the periods is statistically significant for the WR and FR (Table 2). In the BCR, MRRs are also higher, but the differences between the periods are less pronounced and not significant.

Some of the excess mortality in the lowest educated groups is explained by employment status. In 1991-1995, mainly the mortality rates of the primary educated were influenced by unemployment, while in 2001-2005 the all educational levels are influenced (e.g. $\mathrm{MRR}_{\mathrm{WR} \text {-01-low sec-model1 }}=$

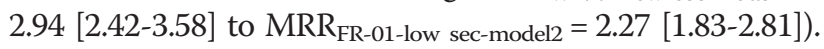
After these controls, we still observe strong educational inequalities among young men, in all regions and time periods.

In model 3, we observe that in most cases, nationality of origin does not alter the results much, with the exception of the BCR in 2001-2005, showing an increase in mortality between model 2 and model 3, especially pronounced in the primary educated $\left(\mathrm{MRR}_{\mathrm{BCR}-01 \text {-primary-model2 }}=2.08\right.$

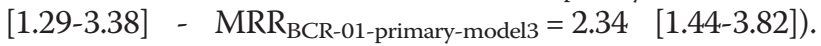
After taking into consideration that most non-Belgians show lower mortality risks compared to Belgians [29] and generally have a lower educational attainment than Belgians, educational inequalities increase in the BCR.

Relative mortality inequalities among women also become more substantial over time (Table 6), especially in the FR. The MRR for the primary educated compared to the higher educated increased from 1.86 [1.54-2.25] in 1991-1995 to 3.69 [2.76-4.95] in 2001-2005 (model 1). Mortality rates are significantly higher for both the primary and the lower secondary educated in the FR, only significantly higher among the higher secondary educated in the WR, and even significantly lower among the lower secondary educated in the BCR in 2001-2005 (Table 2).

Few differences are statistically significant among women in the BCR in 2001-2005, which is partly due to fewer deaths compared to 1991-1995. The mortality rates are also more comparable between educational levels, except for the primary educated. These are no longer significantly different from mortality among the highest educated in model $2 / 3$ (e.g. MRR $_{\text {BCR-01-primary-model } 3}=1.59$ [0.86-2.95]).

After controlling for employment in the other regions, the relative inequalities are also considerably reduced in 
Table 6 All-cause mortality rate ratios and confidence intervals among young-adult WOMEN in Belgium by region for 1991-1995 and 2001-2005 (reference category = higher education)

\begin{tabular}{|c|c|c|c|c|c|c|c|}
\hline & & \multicolumn{3}{|l|}{$91-95$} & \multicolumn{3}{|l|}{ 01-05 } \\
\hline & & Model 1 & Model 2 & Model 3 & Model 1 & Model 2 & Model 3 \\
\hline \multirow[t]{6}{*}{$\overline{F R}$} & Higher sec & $1.28^{* *}$ & 1.19 & 1.19 & $1.51^{* * *}$ & $1.25^{*}$ & $1.24^{*}$ \\
\hline & & {$[1.07,1.54]$} & {$[0.99,1.44]$} & {$[0.98,1.44]$} & {$[1.25,1.82]$} & {$[1.02,1.53]$} & {$[1.00,1.52]$} \\
\hline & Lower sec & $1.55^{* * *}$ & $1.32^{*}$ & $1.33^{*}$ & $2.19^{* * *}$ & $1.51^{* *}$ & $1.56^{* * *}$ \\
\hline & & {$[1.25,1.92]$} & {$[1.04,1.66]$} & {$[1.05,1.67]$} & {$[1.72,2.78]$} & {$[1.16,1.97]$} & {$[1.20,2.04]$} \\
\hline & Primary & $1.86^{* * *}$ & $1.42^{* *}$ & $1.46^{* * *}$ & $3.69^{* * *}$ & $2.01^{* * *}$ & $2.47^{* * *}$ \\
\hline & & {$[1.54,2.25]$} & {$[1.15,1.77]$} & {$[1.18,1.82]$} & {$[2.76,4.95]$} & {$[1.46,2.78]$} & {$[1.78,3.43]$} \\
\hline \multirow[t]{6}{*}{$B C R$} & Higher sec & $1.93^{* *}$ & $1.89^{* *}$ & $1.95^{* *}$ & 1.18 & 1.01 & 1.07 \\
\hline & & {$[1.23,3.03]$} & {$[1.20,2.98]$} & {$[1.23,3.08]$} & {$[0.74,1.88]$} & {$[0.62,1.66]$} & {$[0.659,1.748]$} \\
\hline & Lower sec & $2.21^{* *}$ & $1.78^{*}$ & $1.94^{* *}$ & 0.99 & 0.75 & 0.78 \\
\hline & & {$[1.36,3.58]$} & {$[1.08,2.94]$} & {$[1.17,3.20]$} & {$[0.56,1.77]$} & {$[0.40,1.39]$} & {$[0.42,1.47]$} \\
\hline & Primary & $2.37^{* * *}$ & 1.59 & $1.96^{* *}$ & $2.34^{* *}$ & 1.42 & 1.59 \\
\hline & & {$[1.54,3.66]$} & {$[0.99,2.56]$} & {$[1.21,3.15]$} & {$[1.40,3.91]$} & {$[0.78,2.58]$} & {$[0.86,2.95]$} \\
\hline \multirow[t]{6}{*}{ WR } & Higher sec & 1.06 & 1.03 & 1.04 & $1.53^{* * *}$ & 1.15 & 1.16 \\
\hline & & {$[0.84,1.34]$} & {$[0.81,1.31]$} & {$[0.82,1.33]$} & {$[1.22,1.93]$} & {$[0.90,1.48]$} & {$[0.90,1.49]$} \\
\hline & Lower sec & $1.30^{*}$ & 1.15 & 1.20 & $1.73^{* * *}$ & 1.05 & 1.07 \\
\hline & & {$[1.02,1.65]$} & {$[0.89,1.48]$} & {$[0.93,1.55]$} & {$[1.33,2.25]$} & {$[0.79,1.42]$} & {$[0.80,1.44]$} \\
\hline & Primary & $1.86^{* * *}$ & $1.42^{* *}$ & $1.50^{* *}$ & $2.70^{* * *}$ & 1.38 & $1.54^{*}$ \\
\hline & & {$[1.48,2.32]$} & {$[1.10,1.83]$} & {$[1.16,1.94]$} & {$[1.90,3.84]$} & {$[0.94,2.03]$} & {$[1.05,2.26]$} \\
\hline
\end{tabular}

Data: census 1991, 2001 linked to national register, own calculations.

${ }^{* * *}: \mathrm{p}<0.001 ;{ }^{* *}: \mathrm{p}<0.010 ;{ }^{*}: \mathrm{p}<0.050$.

$\mathrm{FR}=$ Flemish Region, $\mathrm{BCR}=$ Brussels-Capital Region, $\mathrm{WR}=$ Walloon Region

Model 1: Controlled by age/Model 2: Controlled by age and employment situation/Model 3: Controlled by age, employment situation and nationality of origin.

both periods $\left(\mathrm{MRR}_{\mathrm{WR}-91 \text {-primary-model } 2}=1.50\right.$ [1.16-1.94]; MRR $_{\text {WR-01-primary-model } 2=1.54}$ [1.05-2.26]). Employment situation influences not only the mortality rates of the lowest educated groups, but also those of higher secondary educated women (e.g. $\mathrm{MRR}_{\mathrm{FR}-01 \text {-higher sec-model1 }}=1.51$ [1.25-1.82] compared to $\mathrm{MRR}_{\mathrm{FR}-01 \text {-higher sec-model2 }}=1.24$ [1.00-1.52]).

\section{Discussion}

\section{Main findings \& interpretation}

This paper depicted educational inequalities in mortality among young adults in three Belgian regions over time. We observed a general positive trend towards substantial lower mortality in most educational groups in both men and women and found persisting inequalities over time in all regions.

Concerning regional differences in men, young-adult mortality was highest in the WR in the 1990s and 2000s. There was an overall decrease in male mortality in each observation period in the three regions, but not in each educational level. In the $\mathrm{BCR}$, the spectacular decrease in mortality was partly due to a large drop in mortality both at the lower and at the higher end of the educational distribution. Over the entire observation period, mortality decreased more among the higher educated
(65\%) than among the primary educated (27\%). In the WR we also observed stronger declines among the highest educated compared (32\%) to the primary educated (8\%), while there also is a small increase among the lower secondary educated (7\%). In the FR we observed increases in mortality among the two lowest educated groups (16 and 21\%). After controlling for nationality of origin and employment situation, the relative inequalities between regions become more comparable. Part of the male mortality decrease among the lowest educated men in the BCR can thus be attributed to the different population distribution in 2001 compared to 1991. A larger proportion of non-Belgians such as Turks and Maghrebins are living in the BCR than in the other regions. It has been well established that these groups have a lower mortality than the host population $[29,30]$ and are overrepresented in the lower educated levels [32].

In women, young-adult mortality is a lot less common compared to men in all observed periods. For example, female mortality is $50 \%$ lower in the BCR, $53 \%$ in the FR and 57\% lower in the WR compared to men in 20012005. Regional differences over time are similar to that of men, though the general declines over time are more modest, in part because the female mortality level in the 1990s was much lower than that of men to begin with. 
The only difference in general trends in all-cause mortality over time is that women in the FR still have the lowest mortality rates in 2005-2009, while the BCR showed lower mortality rates among men in this period. Concerning educational inequalities over time, we observe some sex differences in 2001-2005 in the BCR. While male mortality dropped in all educational categories, mortality among primary educated women only slightly decreased compared to the other educational groups. After accounting for employment situation, relative educational inequalities are significantly reduced, suggesting that the double deprivation of low education and not being employed makes young-adult women especially vulnerable. Earlier research also points in this direction, showing higher cause-specific mortality from most causes in primary educated women in the BCR [12].

Interpretation of persisting inequalities in mortality over time is a complex matter, as the educational composition of the population has also changed considerably over time. Both the democratization of education and the lengthening of compulsory education are at play here: there is an increased proportion of higher educated (from 23\% to 33\%) and a dwindling fraction of primary educated (18\% to less than $5 \%)$. The primary and lower secondary educated have become a selective group of young persons. Many of these young persons have experienced or are experiencing health and/or psychological problems. This has been noticed among the total adult population in Belgium [33] as well as in different European countries [5]. It used to be common practice to sever the educational track because of job opportunities, but after the 1983 reform, which extended compulsory education until the age of 18 [34], it has become rare to quit education before finishing secondary education. Early-school leaving is then often a blurred story in which both selection and causation occur simultaneously [35,36]. A part of this group probably needs long-term or even life-long care, support and supervision in order to render them good prospects in life in general, and specifically in terms of job opportunities and health and well-being. More discussion is needed on the ways in which to give these persons the capability to enhance their state of health, despite deprivation in their young lives outside of their own choice [37].

Health selection is but one part of the story: poor school performance and problem behaviour and a deprived family background [38] are also influencing factors, leading to few or unstable job opportunities and more risk behaviour [39]. Alienation from school has been associated with health-compromising behaviour such as drug abuse and violence [40,41]. It is clear that early school leaving has severe consequences both on an individual and societal level and that preventing dropout and its negative consequences requires ensuring a close connection between educational, social and employment services both at the national and local level [38].

The question raised here is whether we can speak of increased inequalities over time, if the early schoolleavers become a small and partly selective group, different from the other educational groups? As Mackenbach [42] points out, it may be possible that widening or persisting relative inequalities are the consequence of the democratization of education which made it possible for many young people to attain a certificate of higher education. Hence, the ones being left out may present a selective group in terms of health and other characteristics (see earlier paragraphs). Regarding the higher mortality rates among higher secondary educated, other mechanisms are at work. Although employment status explained some of the excess mortality in these educational groups, mortality remains 60 to $90 \%$ higher compared to the highest educated in the different regions. Multiple health advantages of each extra years of schooling, in terms of knowledge acquisition, means and social contacts are all related to these differences [16]. Although democratisation of education opened up higher education for all, there are limits to the share of the population with a higher education diploma. A broader discussion, beyond the educational system, on equal (health) opportunities for all is needed in this context.

However, all is not negative. The democratisation of education may have resulted in persisting relative inequalities, it definitely brought along absolute mortality declines. This is in line with research conducted in the general adult population [33], and shows that there is no dilution of the effect of education over time. The longterm effects of educational investments cannot be denied. As a recent article concerning increased participation in higher education concluded [43]: further improvements in educational attainment are still possible and can lead to substantial health gains.

\section{Regional differences in an international perspective \& further research}

Regional differences within Belgium have already been identified in the 1970s [21]. Thirty years later we still observe higher mortality in the WR compared to the other regions. Research not specifically focusing on mortality even found a worsening trend in health in some highlydeprived districts within the WR in the last decennia and called for community-level initiatives to bring a halt to the negative spiral this region finds itself in [44]. Our research further suggests that initiatives should be taken relatively early in life. Including meso-level organizations, such as schools, youth organisations and employment institutions, in prevention efforts would be a huge step forward in realizing long-term health benefits. We found higher mortality in the WR for each educational 
level compared to persons with the same educational level in the other regions in 2001-2005. Overall regional differences may partly be attributed to higher deprivation in the WR. Further research is necessary to identify other factors related to the higher mortality in the WR.

Belgium is not an isolated case in its regional mortality differences. In other European countries, considerable regional differences in absolute and relative mortality inequalities have also been observed [21]. A well-known example of within-country differences is Great Britain, with a large North-south divide between England and Scotland persisting over time $[45,46]$. While there is an overall decrease in mortality in Scotland, with reductions being greatest among socially advantaged groups, an increase in excess mortality has been observed among young adult men (15- to 44-year olds) in the last decades. Social patterning was found when probing into cause-specific mortality, with suicides, drug deaths, alcohol and violence as the main contributors to mortality inequalities $[8,45]$.

In order to pinpoint domains at which future prevention efforts should be targeted in Belgium, information on cause-specific mortality is needed. Data on causespecific mortality in the WR are however not available for the observed period. Up till now, census-linked cause-of-death information, covering the period 19912009, is available, available for the FR and BCR only. Unavailability of this kind of information for the WR further hampers the identification of the underlying mechanisms and, hence, the development of tailored policies and prevention campaigns. Nationwide information on cause-specific mortality will be available soon, allowing for an update of information for the WR and, hence, providing more specific insights in order to lower mortality in this region.

\section{Strengths \& limitations}

This is the first study that analysed regional mortality differences among young adults in Belgium over time, taking the three Belgian regions (FR, WR and the BCR) into account. Most studies only compare the FR and WR, leaving out an important part of Belgium. We are aware that the setting of the BCR, as a large urban area, is different from that of the other regions, especially in terms of ethnic composition of the population and other urban dynamics. Comparisons over time may not be as straightforward due to the design of our study, as the start population at each census time differs in composition because of the selective influx of migrants, especially in the BCR. To take these differences in composition into account, we controlled for nationality of origin in our regression analysis.

The high-quality data with complete follow-up on deaths and emigrations over a considerably large period make detailed analyses possible. Individually-linked mortality data furthermore rule out common numeratordenominator problems, amongst other biases [47]. Unfortunately, we do not have updated information on employment situation for the in-between periods 19951999 and 2005-2009. Therefore, detailed comparisons for the in-between periods are not possible.

\section{Conclusion}

There is an overall positive trend towards lower allcause mortality over time in Belgium. Educational inequalities are found in each observation period and region and in both men and women. The results are in line with research focusing on the persistence of social inequalities in mortality in the general adult population [4-6]. The results also show that the low educated become a small and selective group with high mortality risks. This calls for a debate on the responsibility of society in rendering support and capability to enhance the state of health and well-being of those not able to achieve a similar social status as their peers. The situation in the WR underlines the importance of good data to monitor trends in cause-specific mortality in order to develop tailored preventive efforts and and to put a halt to the worrying position the region finds itself in.

\section{Additional files}

Additional file 1: Table S1. Absolute and relative mortality differences per 100,000 person years over time among young-adult MEN in Belgium. Additional file 2: Table S2. Absolute and relative mortality differences per 100,000 person years over time among young-adult WOMEN in Belgium.

\section{Abbreviations \\ FR: Flemish Region; BCR: Brussels-Capital Region; WR: Walloon Region; ASMR: Age-standardised mortality rate; MRR: Mortality rate ratio; SEP: Socioeconomic position.}

Competing interests

The authors declare that there are no competing interests.

\section{Authors' contributions}

HDG was involved in the conception of the study, performed all the statistical analyses, interpreted the data, drafted the article and revised the text to include the remarks of the other authors and the comments of the reviewers. HV reflected on methodological issues, helped to decide on the measures to use and present in the article, read and revised the article on content and spelling. PD helped to develop the research design, reflected on the results and interpretation, read the article and gave ideas for improvement. All authors read and approved the final version of the article.

\section{Acknowledgements}

This research is funded by the Brussels-Capital government, as a Prospective Research for Brussels project of Innoviris. We are thankful to Didier Willaert, who is always there to help with data preparations.

Received: 14 September 2014 Accepted: 20 December 2014

Published online: 16 March 2015 


\section{References}

1. McMichael AJ, McKee M, Shkolnikov V, Valkonen T. Mortality trends and setbacks: global convergence or divergence? Lancet. 2004;363(9415):1155-9.

2. Patton GC, Coffey C, Sawyer SM, Viner RM, Bose K, Vos T, et al. Global patterns of mortality in young people: a systematic analysis of population health data. Lancet. 2009;374(9783):881-92.

3. Tuljapurkar S, Li N, Boe C. A universal pattern of mortality decline in the G7 countries. Nature. 2000;405(6788):789-92.

4. Eikemo TA, Huisman M, Bambra C, Kunst AE. Health inequalities according to educational level in different welfare regimes: a comparison of 23 European countries. Sociol Health III. 2008;30(4):565-82.

5. Mackenbach JP, Kulhánová, I, Menvielle, G, Bopp, M, Borrell, C, Costa, G, for the Eurothine and EURO-GBD-SE consortiums. Trends in inequalities in premature mortality: a study of 3.2 million deaths in 13 European countries. J Epidemiol Commun H. 2014, doi:10.1136/jech-2014-204319.

6. Marmot M. Review of social determinants and the health divide in the WHO European Region: final report. Copenhagen: WHO Regional office for Europe; 2013.

7. Borrell C, Pasarin Ml, Cirera E, Klutke P, Pipitone E, Plasencia A. Trends in young adult mortality in three European cities: Barcelona, Bologna and Munich, 1986-1995. J Epidemiol Commun H. 2001;55(8):577-82.

8. Mcloone P. Increasing mortality among adults in Scotland 1981 to 1999 Eur J Public Health. 2003;13(3):230-4.

9. Nylén G, Mortimer J, Evans B, Gill N. Mortality in young adults in England and Wales: the impact of the HIV epidemic. AIDS. 1999;13(12):1535-41.

10. Sells CW, Blum RW. Morbidity and mortality among US adolescents: an overview of data and trends. Am J Public Health. 1996;86(4):513-9.

11. Cesaroni G, Agabiti N, Forastiere F, Ancona C, Perucci CA. Socioeconomic differentials in premature mortality in Rome: changes from 1990 to 2001 BMC Public Health. 2006;6(270):1-6.

12. De Grande $H$, Deboosere $P$, Vandenheede $H$. Evolution of educational inequalities in mortality among young adults in an urban setting. Int $J$ Public Health. 2013;58(6):825-35.

13. Galobardes B, Shaw M, Lawlor DA, Lynch JW, Smith GD. Indicators of socioeconomic position (part 1). J Epidemiol Community Health. 2006:60(1):7-12

14. Eide ER, Showalter MH. Estimating the relation between health and education: what do we know and what do we need to know? Econ Educ Rev. 2011;30(5):778-91.

15. Baker DP, Leon J, Smith Greenaway EG, Collins J, Movit M. The education effect on population health: a reassessment. Popul Dev Rev. 2011;37(2):307-32.

16. Ross CE, Wu C. The links between education and health. Am Soc Rev. 1995:60(5):719-45

17. Lynch JW, Kaplan GA, Salonen JT. Why do poor people behave poorly? Variation in adult health behaviours and psychosocial characteristics by stages of the socioeconomic lifecourse. Soc Sci Med. 1997;44(6):809-19.

18. Dibben C, Popham F. Are health inequalities evident at all ages? An ecological study of english mortality records. Eur J Public Health. 2013;23(1):39-45.

19. Goldman D, Smith JP. The increasing value of education to health. Soc Sci Med. 2011;72(10):1728-37.

20. Lynch SM. Cohort and life-course patterns in the relationship between education and health: a hierarchical approach. Demography. 2003;40(2):309-31.

21. Shaw M, Orford S, Brimblecombe N, Dorling D. Widening inequality in mortality between 160 regions of 15 European countries in the early 1990s. Soc Sci Med. 2000;50(7-8):1047-58.

22. Humblet $P C$, Lagasse $R$, Levêque $A$. Trends in Belgian premature avoidable deaths over a 20 year period. J Epidemiol Comm H. 2000;54(9):687-91.

23. Lagasse R, Humblet PC, Lenaerts A, Godin I, Moens GF. Health and social inequities in Belgium. Soc Sci Med. 1990;31(3):237-48.

24. Van Oyen H, Tafforeau J, Roelands M. Regional inequities in health expectancy in Belgium. Soc Sci Med. 1996;43(11):1673-8.

25. Van Oyen H, Bossuyt N, Deboosere P, Gadeyne S, Tafforeau J. Differences in health expectancy indicators in Belgium by region. Arch Public Health. 2002;60:341-62

26. Van Oyen H, Bossuyt N, Deboosere P, Gadeyne S, Abatih E, Demarest S. Differential inequity in health expectancy by region in Belgium. Soz Praventivmed. 2005;50(5):301-10.
27. De Grande $H$, Vandenheede $H$, Deboosere P. Data inventory of health inequalities among adolescents and young adults in the Brussels-Capital Region. Revue Quetelet. 2014, in press.

28. Brussels-Capital Health and Social Observatory. Welzijnsbarometer 2014. Brussel: Gemeenschappelijke Gemeenschapscommissie; 2014.

29. Deboosere P, Gadeyne S. Adult migrant mortality advantage in Belgium: evidence using census and register data. Population E. 2005;60(5-6):655-98.

30. De Grande H, Vandenheede H, Gadeyne S, Deboosere P. Health status and mortality rates of adolescents and young adults in the Brussels-Capital Region: differences according to region of origin and migration history. Eth Health. 2013, 1-22.

31. EUROSTAT. Eurostat regional yearbook 2013. Luxembourg: Publication office of the European Union; 2013.

32. Phalet $K$, Swyngedouw M. Measuring immigrant integration: the case of Belgium. Studi Emigrazione. 2003;152:773-804.

33. Deboosere P, Gadeyne S, Van Oyen H. The 1991-2004 evolution in life expectancy by educational level in Belgium based on linked census and population register data. Eur J Pop. 2009;25(2):175-96.

34. Garrouste C. 100 years of educational reforms in Europe: a contextual database. Luxembourg: Publications Office of the European Union; 2010.

35. Claussen B, Smits J, Naess O, Davey Smith G. Intragenerational mobility and mortality in Oslo: social selection versus social causation. Soc Sci Med. 2005;61(12):2513-20

36. Hagquist CEl. Health inequalities among adolescents - the impact of academic orientation and parents' education. Eur J Public Health. 2007;17(1):21-6.

37. Sen A. Lives, freedom and capabilities. In: The idea of justice. Cambridge, Massachusetts: The Belknap Press of Harvard University Press; 2009. p. 225-53.

38. Lyche CS. Taking on the completion challenge: a literature review on policies to prevent dropout and early school leaving. [http://dx.doi.org/ $10.1787 / 5 \mathrm{~km} 4 \mathrm{~m} 2 \mathrm{t} 59 \mathrm{cmr}-\mathrm{en}]$

39. Byrne D, Smith E. No way back? The dynamics of early school-leaving. No way back? The dynamics of early school-leaving. Dublin: The Liffey press in association with The Economic and Social Research Institute; 2010.

40. Bradshaw CP, O'Brennan LM, McNeely CA. Core competencies and the prevention of school failure and early school leaving. New Dir Child Adolesc Dev. 2008;2008(122):19-32.

41. Nutbeam D, Smith C, Moore L, Bauman A. Warning! Schools can damage your health: alienation from school and its impact on health behaviour. J Paediatr Child H. 1993;29(s1):S25-30.

42. Mackenbach JP. The persistence of health inequalities in modern welfare states: the explanation of a paradox. Soc Sci Med. 2012;75(4):761-9.

43. Kulhánová I, Hoffmann R, Judge K, Looman CWN, Eikemo TA, Bopp M, et al. Assessing the potential impact of increased participation in higher education on mortality: evidence from 21 European populations. Soc Sci Med. 2014;117:142-9

44. Sanderson J, Eggerickx E. Des outils d'aide à la décision: Les indicateurs de condition de vie et de mixité socio-démographique des communes et des quartiers en Belgique. In: Léger J, editor. Cahiers de démographie locale 2009. Strasbourg: Néothèque; 2010.

45. Leyland AH, Dundas R, McLoone P, Boddy FA. Cause-specific inequalities in mortality in scotland: two decades of change: a population-based study. BMC Public Health. 2007;7:172.

46. Campbell M, Ballas D, Dorling D, Mitchell R. Mortality inequalities: Scotland versus England and Wales. Health Place. 2013;23:179-86.

47. Abraído-Lanza AF, Armbrister AN, Flórez KR, Aguirre AN. Toward a theory-driven model of acculturation in public health research. Am J Public Health. 2006:96(8):1342-6. 